\title{
Matérista
}

Revista Matéria, v. 16, n. 4, pp. 857 - 867, 2011

ISSN 1517-7076

http://www.materia.coppe.ufrj.br/sarra/artigos/artigo11459

\section{Evolução microestrutural e alteração de dureza na bainita e na perlita em aços 2,25Cr1Mo após tratamento de envelhecimento}

\author{
RIGUEIRA, G. ${ }^{\text {, }}$ FURTADO, H.C. ${ }^{\text {II }}$, LISBOA, M.B. ${ }^{\text {II }}$, ALMEIDA, L.H. ${ }^{\text {II }}$ \\ ${ }^{\text {I }}$ Centro de Pesquisas de Energia Elétrica - Cepel - Eletrobras 21941-911, Rio de Janeiro, RJ. \\ e-mail: glaucio@cepel.br \\ II Avenida Horácio Macedo, 354, Cidade Universitária - CEP 21941, Rio de Janeiro, RJ. \\ Cid. Universitária - Centro de Tecnologia - Bloco F, Ilha do Fundão - Caixa Postal 68505 \\ Rio de Janeiro, RJ \\ e-mail: heloisa@cepel.br ; mbl@cepel.br ; lha@metalmat.ufrj.br
}

\section{RESUMO}

Os aços 2,25Cr-1Mo são largamente utilizados no parque de geração termelétrica no Brasil, estando em boa parte das caldeiras atualmente em operação, e podem apresentar microestrutura composta de ferritaperlita ou ferrita-bainita. Submetido à fluência, esse material tem suas propriedades degradadas em serviço através de modificações microestruturais típicas, como o coalescimento dos carbonetos originalmente presentes. A extensão das mudanças microestruturais representa, nesse caso, perda de resistência mecânica no material.

Como existe uma aceleração no grau de deformação, que depende da tensão, da temperatura e do tempo, com a degradação, a extensão da deterioração microestrutural pode ser usada como uma medida de dano. Dessa forma, é importante conhecer essas modificações para fornecer suporte às técnicas de previsão de vida residual de componentes fabricados com esse tipo de material.

A degradação do material ferrítico-perlítico é bastante conhecida, mas a literatura ainda não apresenta resultados consistentes quanto à do ferrítico-bainítico. Trata-se, aqui, de um estudo comparativo da evolução microestrutural do aço 2,25Cr-1Mo com as duas microestruturas, perlítica e bainítica, em temperaturas entre 550 e $600^{\circ} \mathrm{C}$ até $2.000 \mathrm{~h}$. Os resultados mostraram que a microestrutura do aço ferríticobainítico é mais estável que a do ferrítico-perlítico. Entretanto, a estrutura bainítica não obedece aos mesmos estágios de degradação, identificados por Toft e Marsden utilizados para classificar a perlita.

Palavras chaves: degradação microestrutural, envelhecimento, materiais para altas temperaturas, bainita.

\section{Microstructural evolution and hardness changes in bainite and pearlite in Cr1Mo 2.25 steels after aging treatment}

\section{ABSTRACT}

The 2.25Cr-1Mo steels are widely used in boilers currently in operation in thermal generation plants in Brazil, and can present a microstructure consisting of ferrite-pearlite or ferrite-bainite. Subjected to creep in operation, the material properties of this steel degrade due to typical microstructural changes such as the coalescence of the carbides originally present in the material. In this case, these microstructural changes reduce the mechanical strength of the material.

Since strain increases with microstructural degradation and strain depends on the stress, temperature and time, the extent of microstructural degradation can be used as a damage measurement method. Thus, it is important to know the microstructural changes in the material to provide technical support for residual life prediction of components.

The degradation of the ferritic-pearlitic steels is well known, but the literature does not present consistent results regarding the ferritic-bainitic steels. This is a comparative study of the microstructural evolution at temperatures between 550 and $600^{\circ} \mathrm{C}$ to $2,000 \mathrm{~h}$ of pearlitic and bainitic $2.25 \mathrm{Cr}-1 \mathrm{Mo}$ steels. The results showed that the ferritic-bainitic steel is more stable than the ferritic-pearlitic. However, the bainitic structure does not present the same stages of degradation identified by Toft and Marsden to classify the pearlitic steels.

Keywords: microstructural degradation, aging, high temperature materials, bainite. 


\section{INTRODUÇÃO}

Os aços Cr-Mo são largamente utilizados em aplicações que envolvem exposição à fluência, notadamente nas indústrias petroquímica e de geração de energia elétrica, na forma de vasos de pressão, tubulações de caldeiras e partes estruturais.

São materiais com boa resistência à corrosão e à fluência, além de apresentarem alta tenacidade e boa soldabilidade, com excelente relação custo/benefício. Simultaneamente, apresentam baixa expansão térmica e alta condutividade térmica. Estes fatores, em conjunto, os tornam materiais bastante atrativos para operar sob condições de altas temperaturas e baixas tensões.

O desenvolvimento contínuo dos dados sobre fluência e microestrutura dá respaldo a investigações de análises de falha e a estimativa de vida residual de componentes operando pressurizados e sob altas temperaturas. Embora a estimativa de vida residual de componentes envelhecidos, e ainda operando em plantas térmicas e processos industriais em geral, tenha atraído muita atenção, uma tecnologia de avaliação de integridade efetiva em termos de custo e de competitividade ainda há de ser desenvolvida [1].

O aço 2,25Cr-1Mo pode se apresentar com dois tipos de microestruturas: ferrítico-bainítica ou ferrítico-perlítica. A ferrita-bainita resulta de um tratamento térmico de normalização e revenimento, enquanto a estrutura composta por ferrita e perlita decorre de recozimento realizado após a normalização e o revenimento.

A literatura relativa a esse material mostra critérios de avaliação de degradação microestrutural estabelecidos e consagrados no que se refere à microestrutura ferrítico-perlítica, como o critério de Toft e Marsden [2], não existindo, entretanto, critério definido quanto à ferrita-bainita. No que diz respeito à degradação microestrutural, observa-se que o aço com estrutura composta por ferrita e perlita passa por fases muito bem definidas de progressiva esferoidização do $\mathrm{Fe}_{3} \mathrm{C}$, além da correspondente queda nos valores de dureza, facilitando sua classificação [2]. Ao contrário, o material com estrutura ferrítico-bainítica apresenta poucas alterações microestruturais resolvíveis por microscopia ótica, mantendo seus valores de dureza no mesmo patamar do material novo, o que impossibilita sua avaliação utilizando-se as técnicas tradicionais.

A microestrutura do aço ferrítico-bainítico é mais estável que o ferrítico-perlítico ao longo do envelhecimento, embora tenha sido observada degradação da bainita. Verificou-se que as duas microestruturas, quando degradadas, podem ser bastante similares, impossibilitando a identificação a não ser que haja conhecimento prévio das fases presentes no material novo.

\section{MATERIAIS E MÉTODOS}

Os aços usados em caldeiras, nos componentes operando sob fluência, são geralmente aços baixa liga com microestrutura formada por ferrita e perlita, ferrita e bainita ou martensita revenida.

A extensão das mudanças microestruturais representa, nesse caso, perda de resistência mecânica no material. Como existe uma aceleração no grau de degradação com a deformação, que depende da tensão, da temperatura e do tempo, a extensão da deterioração microestrutural pode ser usada como uma medida de dano.

Um dos critérios mais usados é o desenvolvido por Toft e Marsden [2], que estudaram tubos de caldeiras $1 \mathrm{Cr}-0,5 \mathrm{Mo}$ retirados de serviço que possuíam microestrutura composta por ferrita e perlita com diferentes tempos de exposição à temperatura. As amostras foram submetidas a ensaios de fluência, para determinar a vida remanescente e foi observada uma relação entre o grau de esferoidização de carbonetos e a tensão de ruptura. Na prática, isto significa identificar o tipo de microestrutura observada num componente e estimar a extensão do dano e a vida residual. A Figura 1 mostra o critério estabelecido por Toft e Marsden [2] para aços de estrutura composta por ferrita e perlita operando sob fluência.

As propriedades mecânicas das ligas utilizadas em plantas térmicas têm grande importância, uma vez que os componentes das usinas de geração de energia elétrica possuem vida operacional limitada em virtude da exposição a altas temperaturas, tensões e ambientes agressivos. A extensão de vida além da prevista em projeto tem, portanto, grande impacto econômico [3]]. 


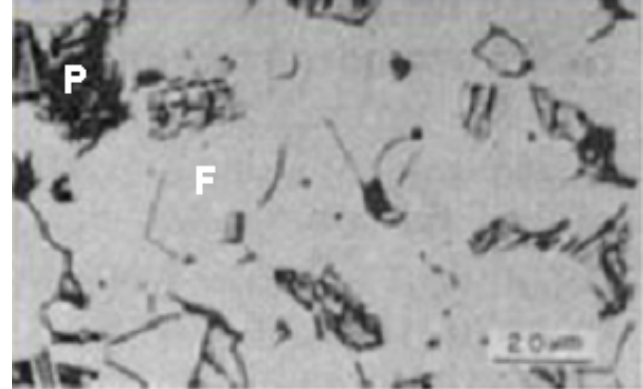

(a)

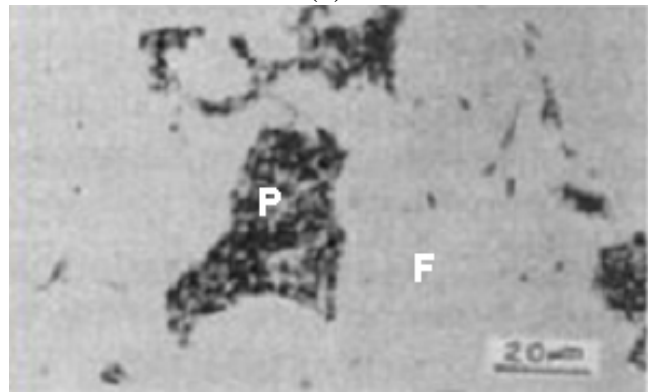

(c)

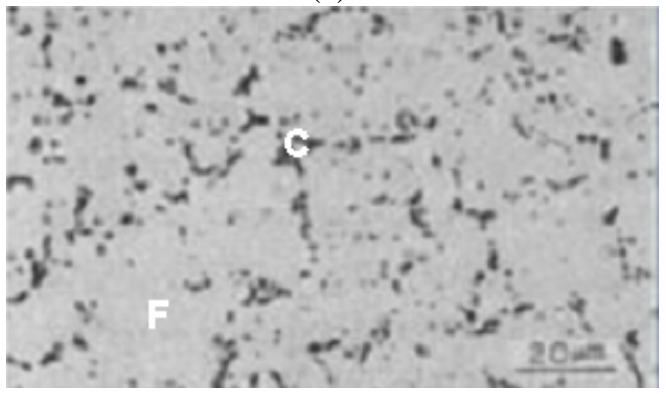

(e)

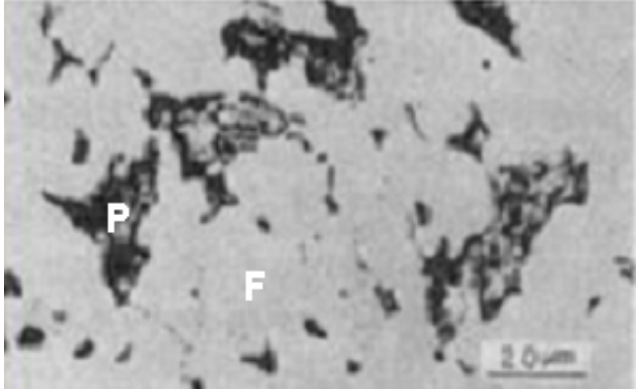

(b)

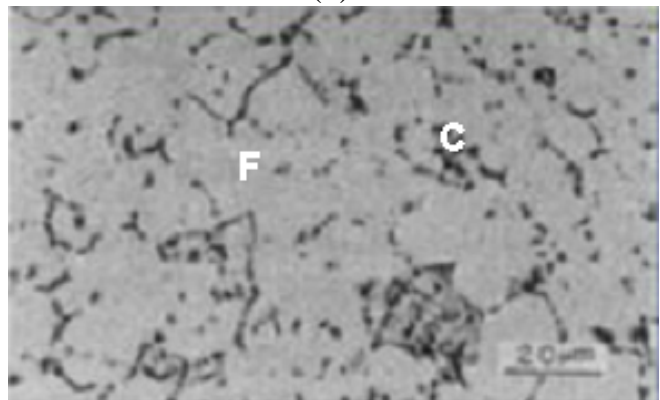

(d)

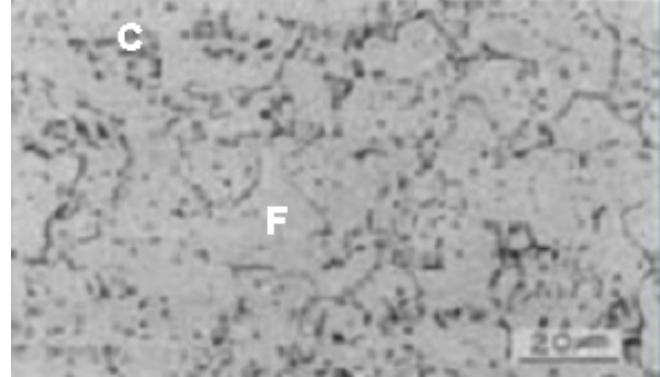

(f)

Figura 1: Critério desenvolvido por Toft e Marsden [2] para aços de estrutura ferrita-perlita. Pode-se notar a progressiva esferoidização da cementita, inicialmente lamelar (a), até um estágio completamente degradado (f), em função da exposição a altas temperaturas ao longo do tempo. F - ferrita; P - perlita; C - carbonetos.

\subsection{Aços 2,25Cr-1Mo}

O aço 2,25Cr-1Mo é o mais encontrado em unidades que operam em altas temperaturas, sendo, por esta razão, aquele mais encontrado na literatura.

Segundo Bhadeshia [4], os principais tipos de aços resistentes à fluência são o 2,25Cr-1Mo, o $1 \mathrm{CrMoV}$ e o $0,25 \mathrm{CrMoV}$, sendo o primeiro o mais resistente entre os três.

Este tipo de material é um dos aços resistentes à fluência mais utilizados para aplicações como plantas químicas, nucleares, usinas termelétricas, além da indústria do petróleo [5], sendo que é a resistência à ruptura por fluência que determina a tensão em que o material pode operar. Consequentemente, na evolução do comportamento em fluência de aços $\mathrm{Cr}-\mathrm{Mo}$, a estimativa de resistência à ruptura após longos períodos de operação é extremamente importante [] $]$.

Na análise de falha de tubos de superaquecedor final, Chaudhuri [] $]$ verificou que as microestruturas do material novo e do que operou sem falha são semelhantes, consistindo de ferrita e bainita. A região falhada, entretanto, apresentava bainita acicular recentemente formada, ou seja, foi verificado que a área da ruptura possuía maior percentual de bainita do que o existente originalmente no material, levando ao aumento localizado de dureza e do limite de resistência à tração, mostrando que, quanto maior a fração volumétrica de bainita, maior será a resistência mecânica do material.

Lisboa [7] ratifica o observado por Chaudhuri [6] no que diz respeito à degradação microestrutural da bainita. Lisboa [7] observou que a busca por uma metodologia baseada em microscopia ótica que 
estabelecesse patamares claros de degradação microestrutural em função da exposição a altas temperaturas das ligas bainíticas usadas em seu trabalho foi inócua. Uma de suas conclusões diz que as alterações foram extremamente discretas, restritas ao ligeiro coalescimento em escala nanométrica e à evolução de carbonetos de Cr menos estáveis.

\subsection{Relação Entre a Dureza e a Resistência à Fluência}

A dureza tem sido utilizada como um método simples de ensaio mecânico não destrutivo para estimar a perda de resistência mecânica e de resistência à fluência. Embora seja empírica, se revela um complemento útil aos métodos metalográficos de avaliação. Entretanto, esforços têm sido feitos para relacionar os valores de dureza de aços ferríticos com a resistência à fluência $[\underline{8}, \underline{9}, \underline{10}]$.

Além disso, este tipo de medida também pode ser utilizado para que se estime a temperatura a que o componente foi submetido quando há falta de dados disponíveis [1]. Isso é feito relacionando a dureza medida com o parâmetro de Larson-Miller, como apresentado na Figura 2.

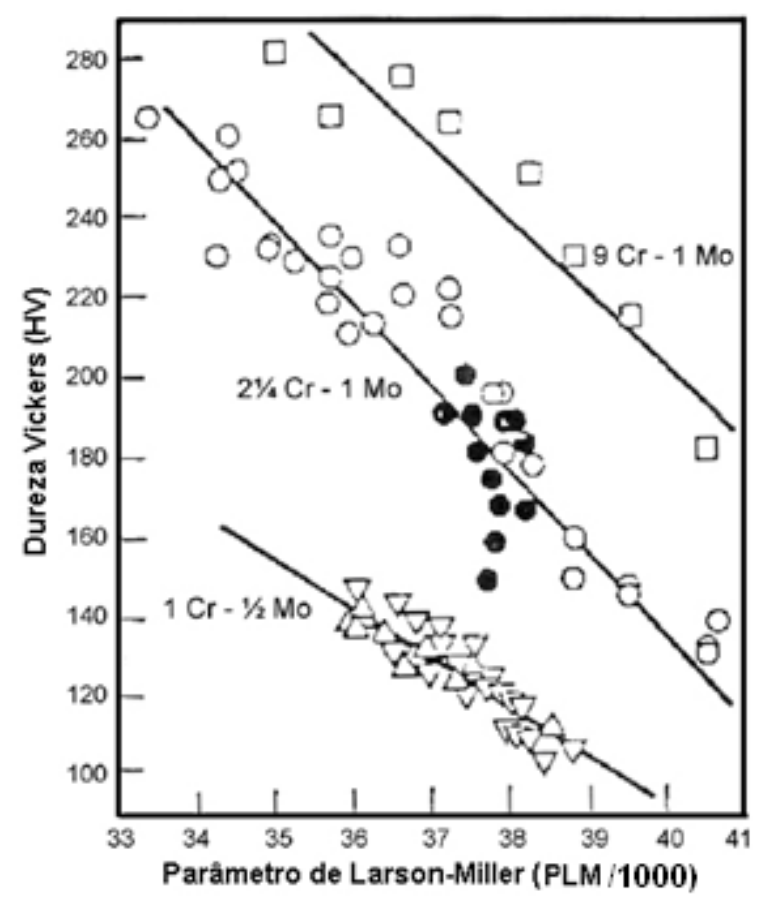

Figura 2: Relação entre dureza Vickers e parâmetro de Larson-Miller para os aços 1Cr-0,5Mo, 2,25Cr$1 \mathrm{Mo}$ e 9Cr-1Mo [1].

A dureza é definida como resistência à deformação, o que quer dizer que suas medidas podem ser usadas para estimar a extensão de danos que ocorreram num material exposto à temperatura e à tensão por um tempo longo. Desta forma, a dureza pode ser usada para uma estimativa dos danos por fluência. Para aços baixa liga, como os usados em plantas de geração, ocorrem perdas de resistência principalmente pelo coalescimento e mudanças morfológicas nos carbonetos.

A recuperação de aços pode ser descrita em termos de um parâmetro tempo-temperatura denominado parâmetro de Hollomon-Jaffee [11] , que é equivalente ao parâmetro de Larson-Miller [1ㅡ] usado para fluência. Pode ser desenvolvida uma relação entre o parâmetro de Larson-Miller, $P L M=(C+\log t f)$, e as mudanças na dureza: se a dureza inicial no tempo $t=0$ é conhecida e igual a $H_{0}$, o material pode ser envelhecido à temperatura $T$ e os valores de $H$ podem ser medidos em tempos diferentes para obter a relação $H=f(P L M)$ para um material em particular. Para medidas de dureza em campo de componentes que estiveram em operação por muito tempo, o valor efetivo ou principal da temperatura à qual eles foram expostos pode ser estimado, desde que os parâmetros $P L M$ e $H_{0}$ sejam conhecidos. Como na maioria dos casos, $H_{0}$ é desconhecido, ele pode ser estimado através de dados conhecidos de materiais similares.

Outra aplicação para as medidas de dureza é relacioná-las com observações microestruturais. Regiões localmente degradadas do material terão uma dureza mais baixa e essas medidas podem fornecer 
indicações suplementares úteis do estado geral de danos por fluência do material, desde que este apresente microestrutura composta de ferrita e perlita.

Lisboa [7], estudando ligas de Fe-Cr-W(V) de microestrutura bainítica, verificou que a tentativa de correlacionar diretamente os valores de dureza Vickers à degradação por fluência não surtiu efeito, uma vez que a perda da resistência das ligas analisadas não encontraram correspondência com uma redução consistente de dureza.

Da mesma forma, Ray et al. [트], estudando o aço 2,25Cr-1Mo, bainítico, que havia operado por 17 anos a $540^{\circ} \mathrm{C}$ e $40 \mathrm{MPa}$, concluiu que "a exposição prolongada do material às condições de operação não produziu qualquer redução relevante de dureza”.

Assim, a operação sob fluência produz redução de dureza mensurável no aço 2,25Cr-1Mo quando este possui microestrutura composta de ferrita e perlita $[\underline{8}, \underline{9}, \underline{10}]$, mas o mesmo não ocorre quando o material é bainítico $[\underline{7}, \underline{13}]$.

\section{MATERIAIS E MÉTODOS}

\subsection{Material Como Recebido}

O aço estudado foi o 2,25Cr-1Mo, de classe ferrítica para aplicação em altas temperaturas, recebido em forma de oito tubos, sendo quatro com microestrutura composta por ferrita-perlita e quatro com estrutura ferrítico-bainítica. Este material é codificado pela ASTM como sendo o aço A 335 - grau 22.

De acordo com o fabricante, para originar a microestrutura ferrítico-bainítica, o material foi submetido à normalização e revenimento, condição padrão de fornecimento, enquanto, para a obtenção de estrutura composta por ferrita e perlita, foi realizado recozimento após os processos mencionados anteriormente.

\subsection{Composição Química}

A composição química do aço 2,25Cr-1Mo recebido e sua comparação com a composição nominal [14], codificado pela ASTM como A335 grau 22 estão apresentadas na Tabela 1. As análises foram realizadas em uma amostra de estrutura ferrítico-bainítica e outra de estrutura composta por ferrita e perlita.

A medida dos teores dos elementos utilizou os seguintes métodos analíticos: combustão direta para o carbono e enxofre, volumetria para o fósforo, gravimetria para o silício e espectrofotometria de absorção atômica no caso do molibdênio, manganês e cromo.

Tabela 1: Composição química do aço analisado e segundo a norma ASTM A 335 G22 [14]]. Os valores são expressos em percentagem em peso.

\begin{tabular}{l|c|c|c|c|c|c|c}
\hline & C & Cr & Mo & Mn & S & P & Si \\
\hline $\begin{array}{l}\text { Ferrita } \\
\text { perlita }\end{array}$ & 0,11 & 1,90 & 0,93 & 0,39 & $<0,001$ & 0,009 & 0,21 \\
\hline $\begin{array}{l}\text { Ferrita + } \\
\text { bainita }\end{array}$ & 0,11 & 1,91 & 0,94 & 0,38 & $<0,001$ & 0,013 & 0,21 \\
\hline $\begin{array}{l}\text { ASTM A } \\
\text { 335 G22 }\end{array}$ & $0,05-0,15$ & $1,9-2,6$ & $0,87-1,13$ & $0,3-0,6$ & 0,025 máx. & 0,025 máx. & 0,5 máx. \\
\hline
\end{tabular}

\subsection{Metalografia}

As análises metalográficas foram conduzidas no laboratório de metalografia do CEPEL, a partir de amostras embutidas em resina epóxi, submetidas a processos de desbaste com lixas: 80, 120, 220, 400, 600 e 1.000. Em seguida, as amostras foram polidas utilizando-se pastas de diamante nas granulometrias 9 e $1 \mu \mathrm{m}$ e atacadas com uma solução para ataque químico de nital 2\%.

As amostras foram analisadas por microscopia de luz visível num banco ótico de platina invertida Olympus GX71.

\subsection{Ensaios de Dureza}

Os ensaios de dureza Vickers - carga de $10 \mathrm{kgf}$ - foram realizados segundo as especificações contidas na norma ASTM E92-82 (2003). 


\subsection{Tratamentos Térmicos de Envelhecimento}

Foram retiradas seções longitudinais de cada tubo, que foram envelhecidas em forno, utilizando-se três temperaturas diferentes $\left(550,575\right.$ e $\left.600^{\circ} \mathrm{C}\right)$, e sendo retiradas com tempos definidos de exposição (100, $500,1.000$ e 2.000 horas).

\section{RESULTADOS E DISCUSSÃo}

\subsection{Evolução Microestrutural com o Envelhecimento}

A estrutura metalográfica do material na condição como recebido é mostrada na Figura 3. Como esperado, é composta de ferrita e perlita sem sinais de degradação, que pode ser classificada como pertencente ao estágio A de degradação segundo o critério de Toft e Marsden [2].

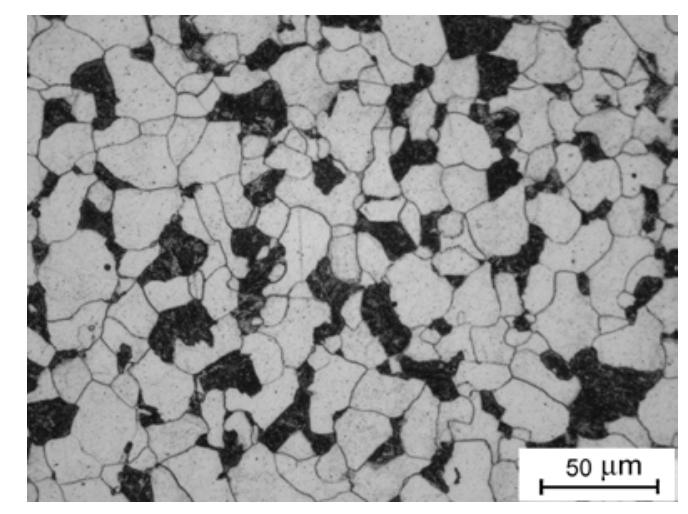

Figura 3: Estrutura metalográfica do material novo, apresentando ferrita e perlita, com ataque por nital 2\%.

A Figura 4 mostra a estrutura metalográfica do material ferrítico-bainítico sem envelhecimento. Pode-se notar a presença de bainita granular e ferrita em toda a região.

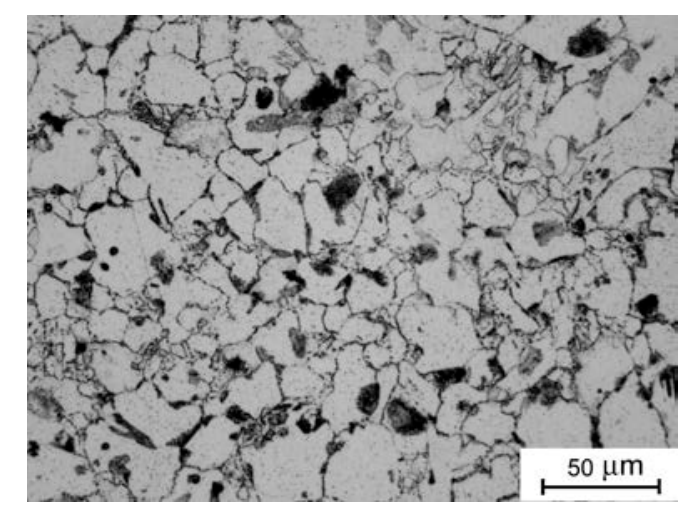

Figura 4: Estrutura metalográfica na condição como recebido, apresentando bainita granular e regiões ferríticas, com ataque por nital $2 \%$.

A evolução microestrutural do aço 2,25Cr-1Mo, observada via microscopia ótica, mostrou que, como esperado, a ferrita-perlita apresenta sinais claros de degradação, com a progressiva esferoidização da cementita, até a sua dissolução total e aumento de precipitação nos contornos de grão, o que está de acordo com o observado na literatura $[2,15]$.

Por outro lado, o aço de mesma composição química, mas de estrutura composta por ferrita e bainita, não mostra sinais tão bem definidos de degradação com a exposição à temperatura ao longo do tempo quando observado por microscopia ótica. O que se pode afirmar é que ocorre aumento da densidade de precipitados na ferrita e nos contornos de grão, além de diminuição da densidade de grãos bainíticos.

A Figura 5 mostra a evolução microestrutural do material de estrutura ferrítico-perlítica ao longo do 
tempo para cada temperatura de envelhecimento, e a Figura 6 mostra o mesmo para o material ferríticobainítico.

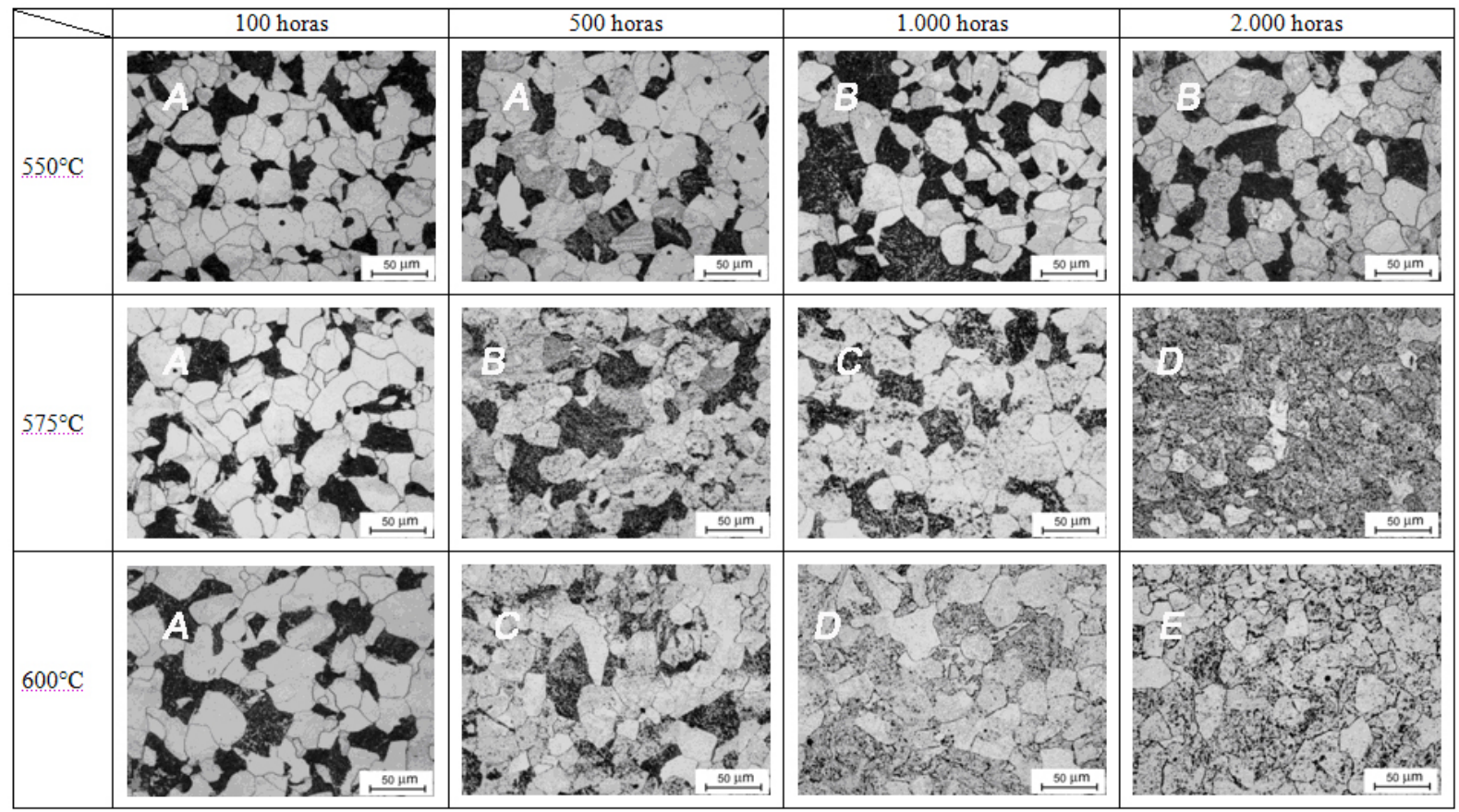

Figura 5: Evolução microestrutural do aço ferrítico-perlítico ao longo do tempo e da temperatura, mostrando os estágios de degradação, segundo o critério de Toft e Marsden [2], de cada etapa de envelhecimento.

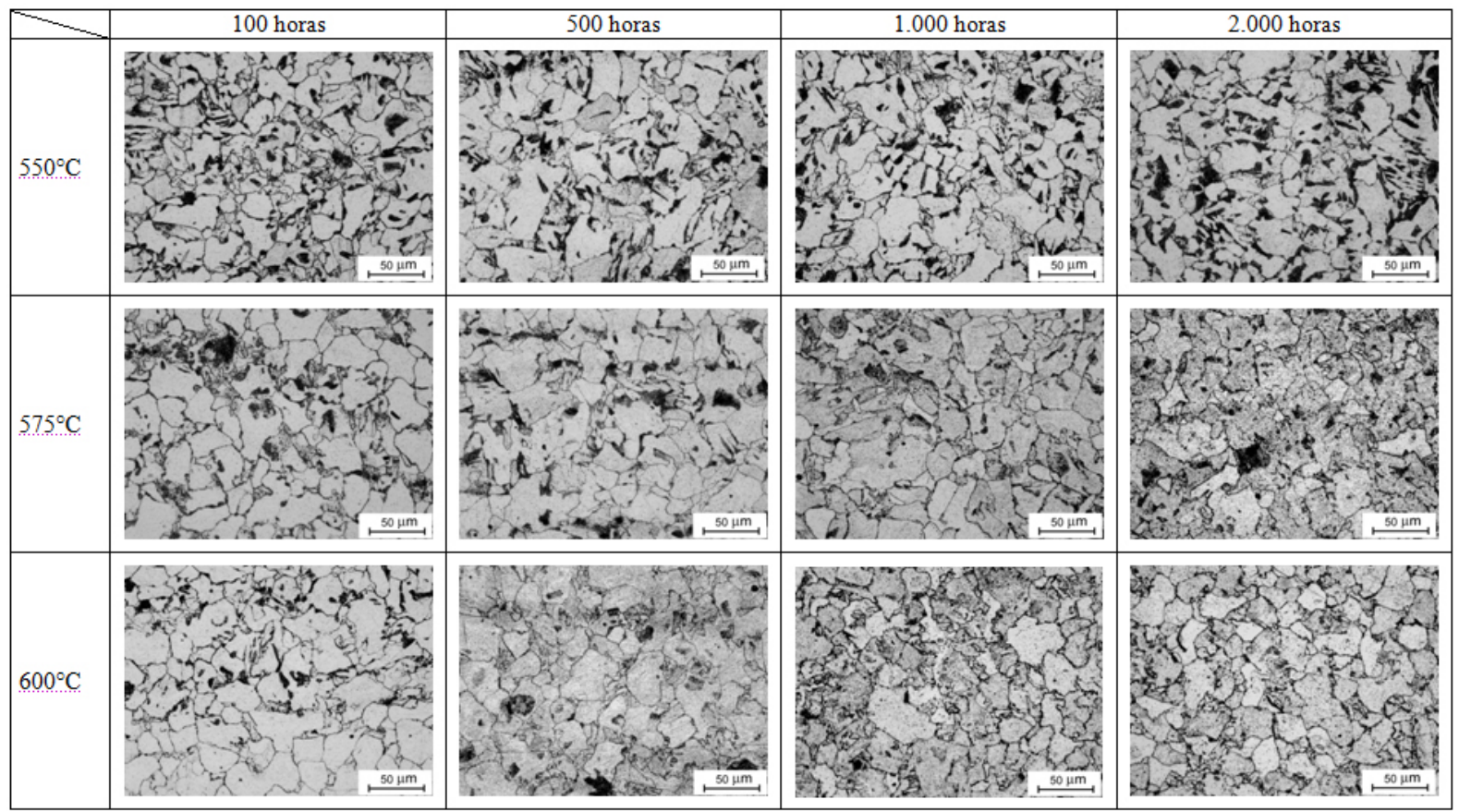

Figura 6: Evolução microestrutural do aço ferrítico-bainítico ao longo do tempo e da temperatura.

Através da análise das Figuras 5 e 6, pode-se notar que as microestruturas referentes ao material perlítico degradado podem ser bastante semelhantes às do material bainítico, tornando a determinação de cada uma fortemente dependente do conhecimento prévio da metalografia do material quando novo.

A estabilidade microestrutural da bainita, comprovada com o uso de microscopia ótica, vem ao 
encontro do que dizem Chaudhuri []ㅡ, Bhadeshia [ㄴ, 16] e Lisboa []]. O primeiro, em análise de falha de tubos de superaquecedor, percebeu que as estruturas, compostas por ferrita e bainita, do material novo e do que operou eram semelhantes. Bhadeshia afirma não ter notado alterações microestruturais no aço 2,25Cr1Mo bainítico. Já Lisboa diz que suas tentativas de correlacionar observações via microscopia ótica e degradação por fluência se revelaram ineficientes. Tanto as observações dos três autores citados quanto os resultados do presente estudo refutam a ASM [17], que diz que a taxa de esferoidização mais lenta é associada a microestruturas perlíticas, e Beere [트, que sugere uma degradação mais rápida da bainita quando comparada à ferrita-perlita.

\subsection{Evolução da Dureza com o Envelhecimento}

A dureza foi medida em dez pontos da região analisada do material como recebido e apresentou

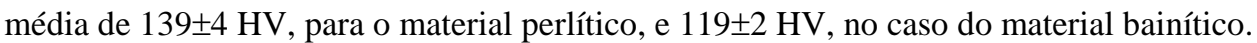

As médias dos valores de dureza de cada condição de envelhecimento foram colocadas em gráficos, apresentados a seguir nas Figuras 7 a 9, a fim de comparar os comportamentos das duas diferentes microestruturas avaliadas, ferrita-perlita e ferrita-bainita.

Para todas as curvas, os valores iniciais são os mesmos, ou seja, os valores de dureza relativos ao material sem envelhecimento.

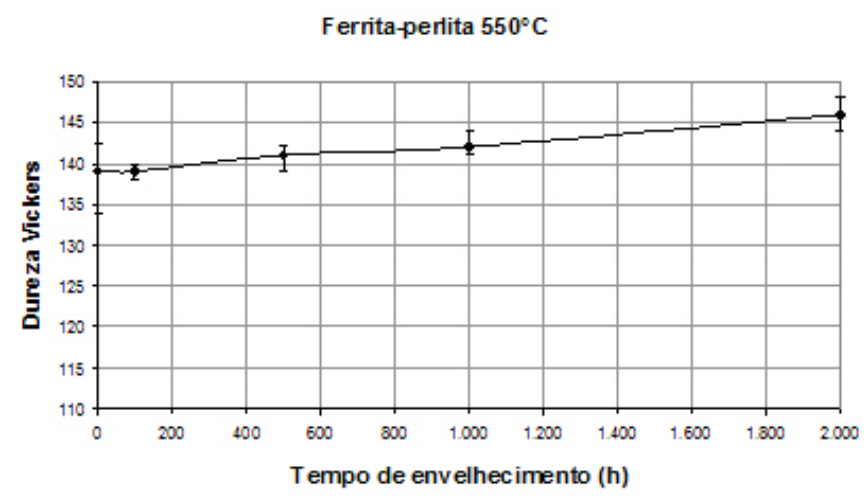

Ferrita-bainita $550^{\circ} \mathrm{C}$

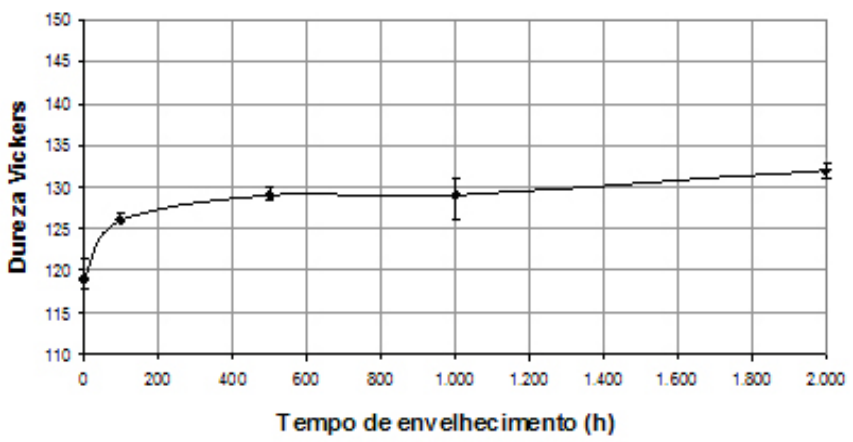

Figura 7: Evolução dos valores de dureza Vickers com o tempo de envelhecimento a $550^{\circ} \mathrm{C}$.

Tanto no caso do aço de microestrutura ferrita-perlita quanto ferrita-bainita, a tendência da dureza é de aumento num primeiro momento e posterior estabilização. O aumento que ocorre está relacionado com o fenômeno de endurecimento secundário.

Pode-se observar que os valores de dureza da estrutura formada por ferrita e perlita estão, em todos os pontos e nas três condições, superiores aos da bainita. Além disso, não há queda perceptível de valores de dureza quando comparados os valores iniciais e finais, mesmo para o material submetido às piores condições de envelhecimento entre as utilizadas.

O aumento inicial de dureza, bem como sua posterior queda e estabilização, observado para as duas microestruturas, está de acordo, como era esperado, com o estudo de Pickering [19], de 1978, que definiu a 
classe dos aços Cr-Mo como sendo de endurecimento secundário.

Ao longo do envelhecimento a $550^{\circ} \mathrm{C}$, a dureza não chega a apresentar queda, exibindo seu valor máximo em 2.000 horas para as duas estruturas. A $575^{\circ} \mathrm{C}$, os pontos de máximo ocorrem em 1.000 horas para a ferrita-perlita e em 500 horas para a ferrita-bainita. Já a $600^{\circ} \mathrm{C}$, os pontos de dureza máxima ocorrem em 500 horas para ambos os casos.

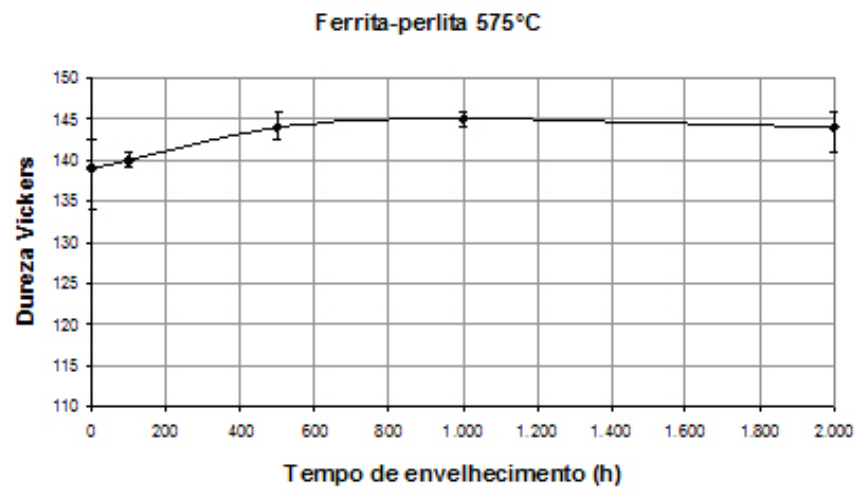

Ferrita-bainita $575^{\circ} \mathrm{C}$

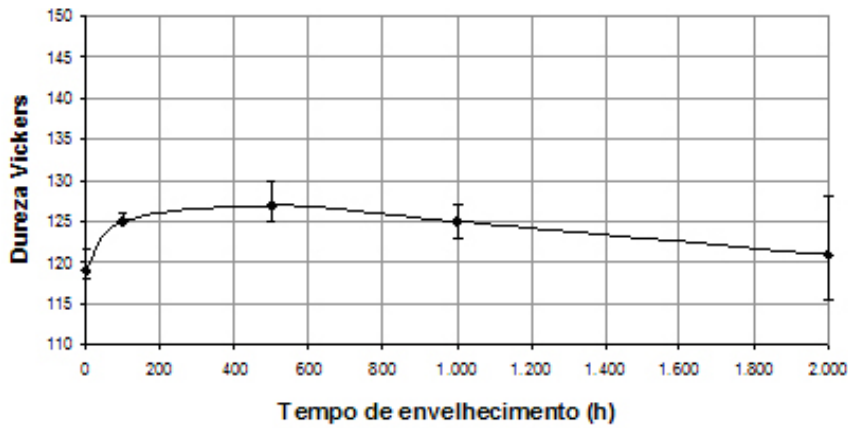

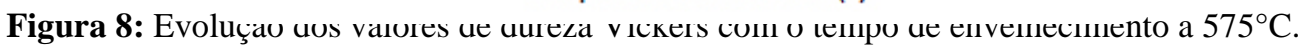

Após o ponto máximo de endurecimento, a dureza sofre ligeira queda ou se mantém estável. De acordo com a literatura, isso era esperado para o material ferrítico-perlítico $[\underline{8}, \underline{9}, \underline{10}]$ e não para a parte de estrutura ferrítico-bainítica [7, 13]. Entretanto, a manutenção da dureza em valores praticamente iguais aos do material novo foi observada para as duas microestruturas. Além disso, levando-se em consideração o desvio padrão das medições de dureza, as diferenças entre a ferrita-perlita e a ferrita-bainita não são suficientes para que se faça uma distinção clara entre as duas.

Dessa forma, o ensaio de dureza, quando usado, deve ser considerado como acessório capaz apenas de detectar variações muito acentuadas. 

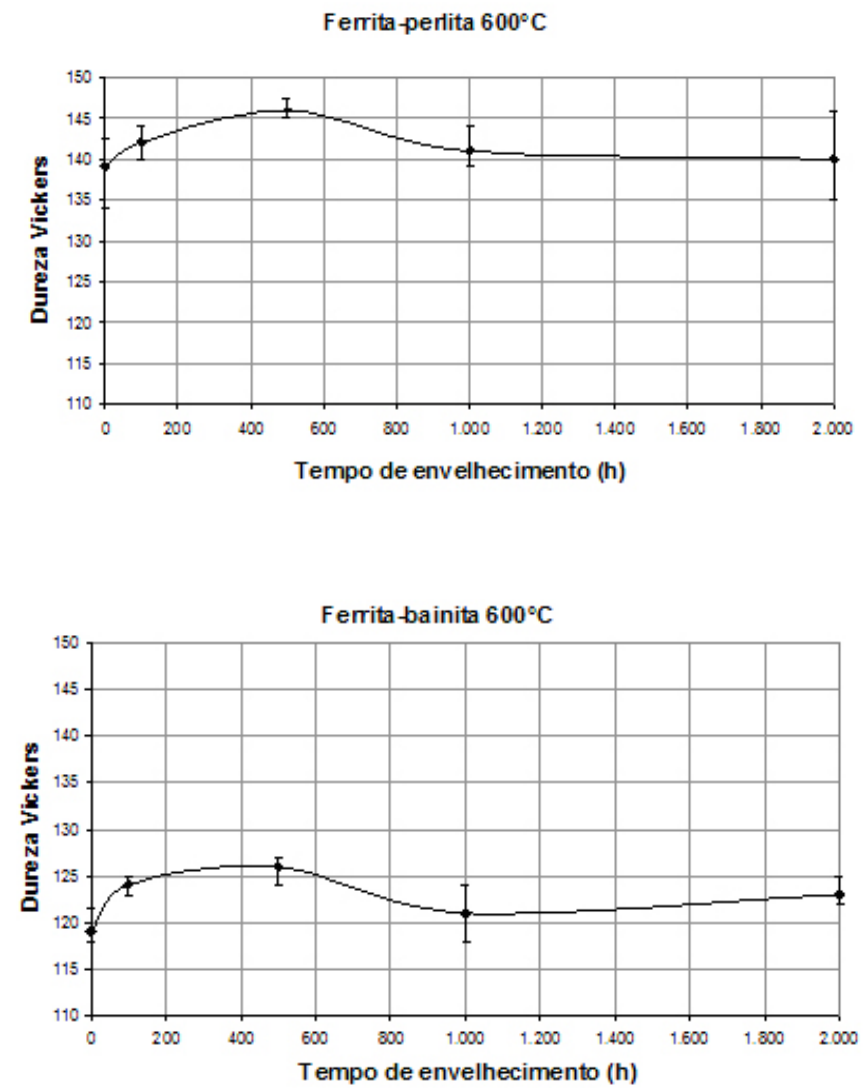

Figura 9: Evolução dos valores de dureza Vickers com o tempo de envelhecimento a $600^{\circ} \mathrm{C}$.

\section{CONCLUSÕES}

Entre as condições utilizadas, a temperatura de $550^{\circ} \mathrm{C}$ não foi suficiente para promover mudanças microestruturais perceptíveis com o uso de microscopia ótica.

Os resultados dos ensaios de dureza revelaram que não há diferenças significativas entre os valores relativos às condições de envelhecimento ou mesmo entre as duas microestruturas avaliadas. Embora o intervalo entre as durezas seja pequeno, os valores referentes à bainita estão, em todos os pontos, abaixo daqueles relativos à perlita. Esses fatos indicam que os resultados de dureza devem ser somente acessórios dentro da avaliação do material.

O endurecimento secundário ocorre em todos os casos analisados, o que pode ser comprovado pela estabilidade dos valores de dureza, embora haja retirada de elementos de liga de solução sólida, nas diferentes condições e microestruturas.

As microestruturas obtidas do material perlítico envelhecido podem facilmente ser confundidas com as do material bainítico. Dessa forma, qualquer análise do aço 2,25Cr-1Mo, seja em campo ou em laboratório, é dependente do conhecimento da sua estrutura inicial.

\section{BIBLIOGRAFIA}

[1] CHAUDHURI, S., "Philosophy of integrity assessment of engineering components", Materials Science and Engineering A, v. 489, pp. 259-266, 2008.

[2] TOFT, L.H, MARSDEN, R.A., "Structural processes in creep: special report no. 70", Iron \& Steel Institute, pp. 238-244, London, 1961. 
[3] RAY, A.K., DIWAKAR, K., PRASAD, B., et al., "Long term creep-rupture behavior of 813 K exposed 2.25Cr-1Mo steel between 773 and 873 K”, Materials Science and Engineering A, v. 454-455, pp. 124-131, 2007.

[4] BHADESHIA, H.K.D.H., “Bainite in steels”, The University Press, Cambridge, 2001.

[5] BYEON, J.W., KWUN, S.I., "Magnetic nondestructive evaluation of thermally degraded 2.25Cr-1Mo steel”, Materials Letters, v. 58, pp. 94-98, June 2003.

[6] CHAUDHURI, S., "Some aspects of metallurgical assessment of boiler tubes - Basic principles and case studies”, Materials Science and Engineering A, v. 432, pp. 90-99, September 2006.

[7] LISBOA, M.B., Nova geração de aços ferríticos Fe-Cr-W(V) - Análise da evolução microestrutural e comportamento mecânico sob condições de fluência, Tese de D.Sc., PEMM/COPPE/UFRJ, Rio de Janeiro, RJ, Brasil, 2007.

[8] KOHLHÖFER, W., PENNY, R.K., “Hardness testing as a means for creep assessment”, International Journal of Pressure Vessels and Piping, v. 66, n. 1-3, pp. 333-339, 1996.

[9] FURTADO, H.C., LISBOA, M.B., ALMEIDA, L.H., "Relação entre dureza e propriedades de resistência à fluência no aço 9Cr-1Mo”, Anais do 63o Congresso Anual da ABM, Santos, SP, 2008.

[10] MASUYAMA, F., "Hardness model for creep-life assessment of high-strength martensitic steels", Materials Science and Engineering A, v. 510-511, pp. 154-157, June 2009.

[11] HOLLOMON, J.H., JAFFEE, L.D., “Time-temperature relations in tempering steel”, Trans. AIME, v. 162, pp. 223, 1943.

[12] LARSON, F.R., MILLER, J., “A time-temperature relationship for rupture and creep stress”, Trans ASME, v. 74, pp. 765, 1952.

[13] RAY, A.K., TIWARI, Y.N., ROY, P.K., et al., “Creep rupture analysis and remaining life assessment of 2.25Cr-1Mo steel tubes from a thermal power plant”, Materials Science and Engineering A, v. 454455, pp. 679-684, April 2007.

[14] KEY TO METALS, disponível em: http://www.keytometals.com. Acessado em 15 de abril de 2009.

[15] FURTADO, H.C., Avaliação de danos em aços ferríticos Cr-Mo operando em regime de fluência, Tese de D.Sc., PEMM/COPPE/UFRJ, Rio de Janeiro, RJ, Brasil, 2004.

[16] BHADESHIA, H.K.D.H., HONEYCOMBE, R.W.K., "Steels, microstructure and properties”, Elsevier Ltd., Third edition, 2006.

[17] ASM, "Properties and selection: irons, steels, and high performance alloys”, Metals Handbook, v. 1, Metals Park, Ohio, 1990.

[18] BEERE, W., "Theoretical treatment of creep cavity growth and nucleation", Cavities and Cracks in Creep and Fatigue, Applied Science, J. Gittus ed., pp. 1-27, London, 1981.

[19] PICKERING, F.B., “Physical metallurgy and design of steels”, Applied Science, London, 1978. 